\title{
Série de Casos de 103 Crianças com Infeção por SARS-CoV-2 em Portugal
}

\section{Case Series of 103 Children with SARS-CoV-2 Infection in Portugal}

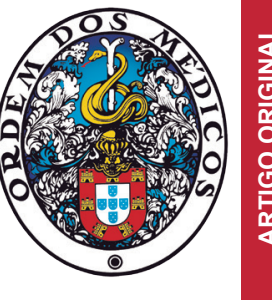

\author{
Clara PICÃO DE CARVALHO ${ }^{1}$, Carolina CASTROํ, Isabel SAMPAIO GRAÇA ${ }^{1,2}$, Cristina LORENZO', \\ Ana BARBOSA RODRIGUES ${ }^{1}$, Rafael INÁCIO ${ }^{1}$, Filipa PRATA ${ }^{1,3}$, Ana MOUZINHO ${ }^{1,3}$, Sara PINTO ${ }^{1,3}$, \\ José Gonçalo MARQUES $\triangle \square^{1,3,4}$ \\ Acta Med Port 2020 Dec;33(12):795-802 - https://doi.org/10.20344/amp.14537
}

\section{RESUMO}

Introdução: O Centro Hospitalar Universitário Lisboa Norte foi ativado para referência de doentes com infeção SARS-CoV-2 em 11 de março de 2020. O objetivo deste estudo é descrever a experiência do Departamento de Pediatria na abordagem e evolução clínica de crianças infetadas.

Material e Métodos: Realizámos um estudo observacional descritivo. Incluímos as crianças e adolescentes (0 aos 18 anos) com infeção por SARS-CoV-2 diagnosticados na urgência e internamento do nosso departamento entre 11 de março e 18 de junho de 2020. Consultámos registos internos e a plataforma Trace COVID-19 e contactámos os cuidadores para avaliação de seguimento.

Resultados: De 103 crianças diagnosticadas, 83\% tiveram contacto prévio identificado com doente infetado, 43\% doentes apresentaram febre e $42 \%$ sintomas respiratórios. Em 10\% havia fatores de risco; $21 \%$ tinham idade inferior a um ano. Foram internadas $10 \%$ das crianças, uma em cuidados intensivos com síndrome inflamatória multissistémica pediátrica. Foi efetuada avaliação laboratorial em $9 \%$, radiografia torácica em $7 \%$. Nenhum recebeu suporte ventilatório, terapêutica antiviral ou realizou tomografia computorizada torácica. Foram reobservadas em serviço de urgência $8 \%$ das crianças, sendo internada uma. A evolução foi conhecida em 101 casos sendo favorável em todos.

Discussão: A maioria dos doentes tinha link epidemiológico familiar e pouca repercussão clínica, mesmo no primeiro ano de vida. A menor gravidade esperada na criança motivou a adoção de critérios habituais noutros quadros clínicos semelhantes para a realização de exames complementares de diagnóstico e internamento hospitalar. Não foi administrada terapêutica antiviral em nenhum doente por se considerar haver pouca evidência de benefício.

Conclusão: Esta estratégia traduziu-se num baixo consumo de recursos hospitalares e revelou-se segura nesta série.

Palavras-chave: Adolescente; COVID-19; Criança; Infecções por Coronavírus/diagnóstico; Portugal; SARS-CoV-2

\section{ABSTRACT}

Introduction: The North Lisbon University Hospital Center was activated for referral of SARS-CoV-2 infected patients on the $11^{\text {th }}$ March 2020. The aim of this study is to describe the experience at the Department of Pediatrics in the approach and the clinical outcomes of infected children.

Material and Methods: A descriptive observational study was performed. Children and adolescents (0 to 18 years) with SARS-CoV-2 infection, diagnosed in the emergency room or admitted to the Department of Pediatrics between March $11^{\text {th }}$ and June $18^{\text {th }}$, were included. Hospital records and Trace COVID-19 platform were reviewed and patient caregivers were interviewed to assess follow up. Results: Among 103 diagnosed children, $83 \%$ had a known previous contact with an infected patient, $43 \%$ presented fever and $42 \%$ presented respiratory symptoms. Ten percent had risk factors and $21 \%$ were aged under one year old. Ten percent were hospitalised one needing intensive care, with paediatric inflammatory multisystem syndrome. Blood tests were performed in $9 \%$ and chest radiograph in $7 \%$. No children required ventilation, antiviral therapy or underwent thoracic computed tomography scan. Eight percent of children returned to the emergency room and one child was hospitalised. The clinical outcome is known in 101 patients and is favourable in all.

Discussion: Most children had an epidemiological link and little clinical repercussion, even during the first year of life. The expected mild severity in children justified the use of established clinical criteria and recommendations for similar conditions, regarding tests and hospitalizations. No antiviral treatments were given due to lack of evidence of its benefits.

Conclusion: This strategy contributed to a low consumption of hospital resources and proved safe in this series.

Keywords: Adolescent; Child; COVID-19; Coronavirus Infection/diagnosis; Portugal; SARS-CoV-2

\section{INTRODUÇÃO}

A pandemia de SARS-CoV-2 foi declarada pela Organização Mundial de Saúde (OMS) no dia 11 de março de 2020. ${ }^{1}$ O primeiro caso em Portugal registou-se a 2 de março. ${ }^{2}$ O Centro Hospitalar Universitário de Lisboa Norte (CHULN), incluindo o Departamento de Pediatria (DdP), foi ativado em segunda linha na abordagem de doentes com coronavirus disease 2019 (COVID-19) no dia 11 de março de 2020.

Por ser uma infeção nova, as recomendações emitidas pela OMS, ${ }^{3}$ pela Direção-Geral da Saúde $(D G S)^{4}$ e pela Sociedade Portuguesa de Pediatria ${ }^{5,6}$ foram sempre consideradas com caráter transitório. O DdP elaborou um protocolo

1. Unidade de Infecciologia e Imunodeficiências. Departamento de Pediatria. Hospital de Santa Maria. Centro Hospitalar Lisboa Norte. Lisboa. Portugal.

2. Serviço de Cardiologia Pediátrica. Hospital de Santa Cruz. Centro Hospitalar Lisboa Ocidental. Oeiras. Portugal.

3. Clínica Universitária de Pediatria. Faculdade de Medicina. Universidade de Lisboa. Lisboa. Portugal.

4. Instituto de Medicina Molecular. Faculdade de Medicina. Universidade de Lisboa. Lisboa. Portugal.

$\triangle$ Autor correspondente: José Gonçalo Marques. jg.marques@chln.min-saude.pt

Recebido: 10 de julho de 2020 - Aceite: 31 de julho de 2020 | Copyright @ Ordem dos Médicos 2020 
de atuação baseado nesses documentos, adequado à sua realidade e que foi sendo adaptado à luz da evolução do conhecimento científico sobre esta patologia.

Os critérios para pesquisa de SARS-CoV-2 foram baseados nas recomendações da DGS. Inicialmente, de acordo com a orientação de 9 de março, ${ }^{7}$ foi realizada aos doentes com febre ou tosse ou dificuldade respiratória que tivessem estado numa área com transmissão comunitária ativa (lista atualizada pela DGS) ou com contacto confirmado com indivíduo infetado, nos 14 dias anteriores. Posteriormente, e de acordo com a orientação de 23 de março, ${ }^{4}$ todos os doentes com febre ou tosse ou dificuldade respiratória foram considerados suspeitos, uma vez que passou a haver transmissão comunitária em Portugal. A partir de 23 de abril, também se passou a fazer pesquisa aos doentes com sintomas gastrointestinais ou odinofagia, de acordo com o protocolo de atuação do DdP do CHULN. O DdP estabeleceu circuitos de atendimento diferenciado em ambulatório, com as colheitas para pesquisa de SARS-CoV-2 no veículo familiar, no estacionamento do Serviço de Urgência Pediátrica (SUPed), sempre que possível, em crianças assintomáticas, com história de contacto com indivíduo infetado ou com necessidade de internamento eletivo. Todos os doentes com necessidade de internamento por qualquer causa foram testados. No internamento foi estabelecida uma ala de isolamento com quartos individuais, dois deles com pressão negativa, destinada a doentes com infeção SARS-CoV-2.

Adotámos os critérios clínicos habituais quer para a realização de exames complementares de diagnóstico quer para o internamento e a alta hospitalar. Como critérios de internamento ${ }^{5}$ foram definidos a ausência de condições de vigilância domiciliária, doença progressiva/prolongada, dificuldade respiratória e/ou apneia, desidratação grave ou vómitos incoercíveis e disfunção de órgão. Relativamente aos critérios de internamento em Unidade de Cuidados Intensivos Pediátricos (UCIPed) foram considerados todos os doentes com pelo menos um dos seguintes ${ }^{6}$ : hipoxemia sem resposta à terapêutica convencional, pneumonia grave, insuficiência respiratória com necessidade de ventilação mecânica, síndrome de dificuldade respiratória aguda e choque séptico ou falência de órgão. Finalmente, foram definidos como critérios de alta a evolução clínica favorável, apirexia mantida há pelo menos três dias, ausência de sinais de desidratação, tolerância alimentar por via oral e sempre que garantidas condições domiciliárias adequadas e ausência de coabitantes pertencentes a grupos de risco.

No presente trabalho pretendemos descrever a abordagem assistencial e evolução clínica das crianças e adolescentes diagnosticados com infeção por SARS-CoV-2 e seguidos no DdP do CHULN até ao dia 18 de junho de 2020 (100 dias).

\section{MATERIAL E MÉTODOS}

Incluíram-se todas as crianças (0 - 17 anos e 364 dias) com resultado positivo para SARS-CoV-2 por colheita de exsudado orofaríngeo e nasofaríngeo, através da técnica reverse transcriptase polymerase chain reaction (RT-PCR), observadas no SUPed e em regime de internamento no DdP do CHULN, de 11 de março a 18 de junho de 2020. Os critérios para pesquisa de SARS-CoV-2 foram baseados nas orientações da DGS ${ }^{4,7}$ e nos protocolos do DdP do CHULN. Foi feito um estudo observacional descritivo.

Foram consultados os registos médicos eletrónicos de atendimento no SUPed e os registos médicos dos processos clínicos eletrónicos e em papel dos doentes internados no DdP, com consentimento verbal dos cuidadores. Para todas as crianças observadas foi preenchido um inquérito epidemiológico com registo da sintomatologia na apresentação. Os cuidadores das crianças atendidas em ambulatório autorizaram o contacto telefónico para comunicação de resultado e inquérito clínico e consulta da plataforma Trace COVID-19 para monitorização da evolução. Esta plataforma é uma ferramenta implementada pela DGS, utilizada pelos profissionais de saúde dos Cuidados de Saúde Primários para fazerem o seguimento clínico dos doentes com suspeita ou confirmação de COVID-19 em ambulatório e para que tomem as medidas de saúde pública indicadas. ${ }^{4}$ Os cuidadores foram contactados passados pelo menos 14 dias desde o diagnóstico e, posteriormente, semanalmente se persistência de sintomas ou ausência de cura microbiológica. Aquando dos inquéritos telefónicos, a sintomatologia foi questionada de forma detalhada pelos investigadores. A cura microbiológica foi determinada por um teste laboratorial negativo, realizado, no mínimo, 14 dias após o início dos sintomas. Nos doentes com necessidade de internamento hospitalar por COVID-19, foram necessários dois testes negativos, com pelo menos 24 horas de diferença. ${ }^{4}$

Analisaram-se os dados demográficos (grupo etário, presença de fatores de risco e existência de contacto com indivíduo infetado), sintomatologia (febre, sintomas respiratórios, sintomas gastrointestinais, sintomas neurológicos e manifestações cutâneas, sensoriais e musculo-esqueléticas), avaliação analítica, radiografia torácica, tomografia computorizada (TC) torácica e outros exames complementares de diagnóstico, internamento hospitalar, terapêutica realizada (antivirais, oxigenoterapia, ventilação mecânica invasiva e não invasiva, suporte aminérgico, imunoglobulina e outros) evolução clínica (critérios de cura microbiológica e persistência de sintomas) e estado vacinal relativo à vacina contra a tuberculose (BCG). A análise por grupo etário baseou-se na descrição de um maior número de complicações associadas a infeção por SARS-CoV-2 no primeiro ano de vida ${ }^{8,9}$ e, particularmente, nos com idade inferior ou igual a três meses, ${ }^{9}$ e na diferente sintomatologia que poderia ser observada no grupo de maiores de 10 anos, mais semelhante à observada no adulto. De acordo com o protocolo do $\mathrm{DdP}$, os fatores de risco considerados foram: doença respiratória crónica, imunosupressão, cardiopatia, doença renal crónica, doença neuromuscular, encefalopatia, doença falciforme, diabetes tipo 1 e doenças metabólicas. ${ }^{5,9}$ A prematuridade, por imaturidade do sistema imune e pulmonar, e a gravidez, por precaução e desconhecimento 
do impacto desta nova infeção, foram também considerados fatores de risco. Considerou-se contacto com caso confirmado ou provável infeção por SARS-CoV-2 em situações de coabitação ou interação próxima, a uma distância inferior a dois metros, por mais de 15 minutos, nos 14 dias anteriores ao início dos sintomas. ${ }^{4}$

Foi criada uma base de dados com todas as crianças e adolescentes a quem foi realizada pesquisa de SARS-CoV-2, da responsabilidade do SUPed e da Unidade de Infecciologia Pediátrica e Imunodeficiências do DdP do CHULN. A base de dados e a análise estatística dos dados foram feitas utilizando o programa Microsoft Excel.

Os dados apresentados respeitam regras de confidencialidade e a sua publicação foi autorizada pela Comissão de Ética do Centro Hospitalar Universitário de Lisboa Norte e do Centro Académico de Medicina de Lisboa.

\section{RESULTADOS}

No período entre 11 de março e 18 de junho de 2020 (100 dias) foram diagnosticadas 103 crianças com infeção SARS-COV-2, de um total de 1278 testes realizados em amostras de exsudado nasofaríngeo e orofaríngeo (Fig. 1).

A mediana da idade das crianças com infeção por
SARS-CoV-2 foi de oito anos (mínimo 14 dias - máximo 17 anos).

Foi identificada história de contacto com doente positivo para SARS-CoV-2 em $83 \%$ dos casos e 10\% apresentavam fatores de risco ( $7 \%$ doença crónica) (Tabela 1). Não foram identificados casos de transmissão nosocomial.

As manifestações clínicas estão agrupadas na Tabela 2. Os sintomas mais frequentes em todos os grupos etários foram a febre $(43 \%)$ e os sintomas respiratórios $(42 \%)$, seguidos dos sintomas neurológicos $(20 \%)$ e gastrointestinais (20\%). Em 54\% dos doentes estavam presentes mais do que um sintoma em simultâneo. A febre esteve presente em $82 \%$ dos lactentes dos quatro aos 11 meses e os sintomas respiratórios em $64 \%$ dos lactentes com idade superior a três meses. Foram observadas cinco crianças com manifestações cutâneas, nomeadamente dois casos de exantema maculopapular, dois casos de lesões papulares e um caso de exantema urticariforme, com envolvimento preferencial dos membros e tronco.

Uma criança de 10 anos teve um quadro grave de síndrome inflamatória multissistémica temporalmente associado à COVID-19 (PIMS-TS) com internamento em UCIPed. Apresentava febre elevada, diarreia, vómitos e exantema

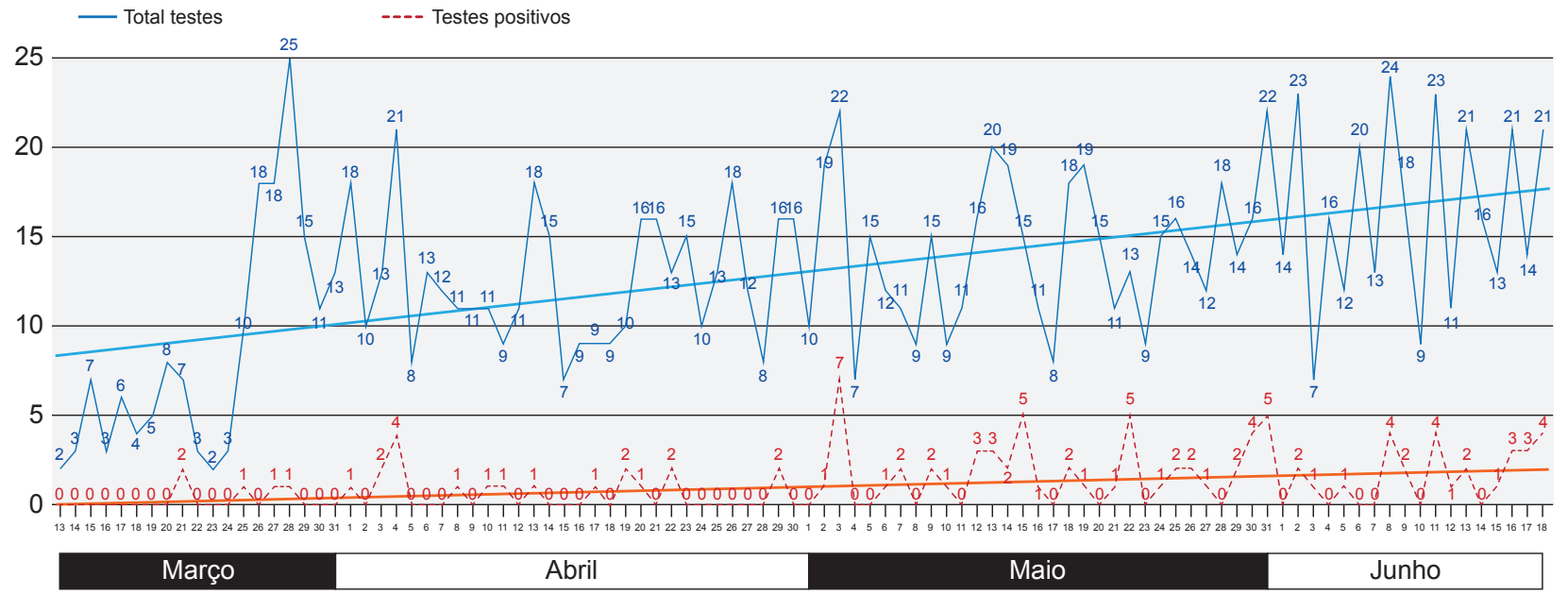

Figura 1 - Número de testes realizados para pesquisa de SARS-COV-2 no exsudado nasofaríngeo e orofaríngeo em idade pediátrica (linha contínua) e número de testes positivos (linha a tracejado)

Tabela 1 - Dados demográficos das crianças e adolescentes com infeção por SARS-CoV-2

\begin{tabular}{cccccc}
\hline & Total & $\leq \mathbf{3}$ meses & $\mathbf{4}-\mathbf{1 1}$ meses & $\mathbf{1}$ ano - $\mathbf{9}$ anos & $\geq 10$ anos \\
\hline $\mathbf{n}(\%)$ & $103(100 \%)$ & $11(11 \%)$ & $11(11 \%)$ & $38(37 \%)$ & $43(42 \%)$ \\
& & $1(9 \%)$ & $1(8 \%)$ & $3(8 \%)$ & $5(12 \%)$
\end{tabular}

Fatores de risco

$10(10 \%)$

Prematuridade

Doença crónica (doença metabólica)

$\begin{array}{ccccc} & \text { Contacto positivo } & 86(83 \%) & 8(73 \%) & 8(73 \%) \\ \text { Contacto } & \text { Familiar } & 81(94 \%) & 8(100 \%) & 7(88 \%) \\ & \text { Outro } & 5(6 \%) & 0(0 \%) & 1(13 \%) \\ & \text { Não identificado } & 17(17 \%) & 3(27 \%) & 3(27 \%) \\ & \text { Infeção } & 0(0 \%) & 0(0 \%) & 0(0 \%) \\ & \text { nosocomial } & 0 & \end{array}$

Prematuridade 1, doença crónica 2 (asma 1, doença metabólica 1)

$32(84 \%)$
$29(91 \%)$
$3(9 \%)$
$6(16 \%)$
$0(0 \%)$

Gravidez 1, doença crónica 4

(asma 2, diabetes 1, transplante renal 1)

$$
\begin{gathered}
38(88 \%) \\
37(97 \%) \\
1(3 \%) \\
5(13 \%)
\end{gathered}
$$


urticariforme, com evolução para choque com hipoxemia. Iniciou suporte aminérgico, imunoglobulina endovenosa, antibioticoterapia e oxigenoterapia com boa evolução clínica.

Vinte e um doentes (20\%) recorreram ao SUPed por contacto positivo, apesar de não apresentarem sintomas.

Efetuaram-se colheitas para avaliação analítica em nove $(9 \%)$ dos 103 doentes com resultado positivo para SARS-CoV-2, sete em regime de internamento e dois que tiveram alta para o domicílio depois de observados no SUPed (um dos quais manteve seguimento em Hospital de Dia por se tratar de uma criança transplantada renal com agravamento da função renal e outro não apresentava alterações laboratoriais). Em três casos houve elevação do valor de PCR (18,5 mg/dL; 21,1 mg/dL; 31,4 mg/dL) associados a quadros de PIMS-TS, artralgia e adenite cervical. Detetámos quatro casos de linfopenia (1139/uL; 937/uL; 698/uL; 600/uL) e um caso de neutropenia (360/uL) num recém-nascido de 24 dias. Observámos três casos de acidose e hiperlactacidémia ( $\mathrm{pH}$ 7,26 e lactatos $36 \mathrm{mg} / \mathrm{dL} ; \mathrm{pH}$ 7,26 e lactatos $51 \mathrm{mg} / \mathrm{dL} ; \mathrm{pH}$ 7,22 e lactatos $41 \mathrm{mg} / \mathrm{dL}$ ), na faixa etária igual ou inferior a três meses. Todas as culturas microbiológicas realizadas nestes doentes foram negati- vas. As alterações laboratoriais indicadas foram transitórias, com regresso a valores normais em todas as crianças em menos de duas semanas (Tabela 3).

Foi realizada radiografia torácica em sete casos $(7 \%)$, três dos quais em internamento (criança de 10 anos com PIMS-TS, recém-nascido de 24 dias e lactente de um mês com febre). Foram observadas alterações em apenas um doente (criança com PIMS-TS com alterações compatíveis com insuficiência cardíaca aguda). Não foi realizada nenhuma tomografia computorizada (TC) torácica.

Foi efetuado ecocardiograma à criança com diagnóstico de PIMS-TS, que revelou ventrículos não dilatados, com discreta redução global da função, sem envolvimento coronário. Foram realizadas ecografia e TC abdominais a um adolescente de 15 anos com quadro de abdómen agudo, com o diagnóstico intra-operatório de oclusão intestinal e divertículo de Meckel. Foi realizada uma ecografia cervical a uma criança de 11 meses com diagnóstico de adenite cervical. Foi realizada uma punção lombar a um recém-nascido de 24 dias com febre.

Das 103 crianças e adolescentes diagnosticados com infeção por SARS-CoV-2, 10 (10\%) apresentaram critérios de internamento, dos quais três por questões sociais.

Tabela 2 - Manifestações clínicas por grupo etário das crianças e adolescentes infeção por SARS-CoV-2

\begin{tabular}{|c|c|c|c|c|c|c|}
\hline & & $\begin{array}{c}\text { Total } \\
(n=103)\end{array}$ & $\begin{array}{c}\leq 3 \text { meses } \\
(n=11)\end{array}$ & $\begin{array}{c}4-11 \text { meses } \\
(n=11)\end{array}$ & $\begin{array}{c}1 \text { ano }-9 \text { anos } \\
(n=38)\end{array}$ & $\begin{array}{l}\geq 10 \text { anos } \\
(n=43)\end{array}$ \\
\hline \multicolumn{2}{|l|}{ Assintomáticos, n (\%) } & $21(20 \%)$ & $1(5 \%)$ & $0(0 \%)$ & $9(43 \%)$ & $11(52 \%)$ \\
\hline \multicolumn{2}{|l|}{$\begin{array}{l}\text { Febre, n (\%) } \\
\text { (mínino - máximo) }^{1}\end{array}$} & $\begin{array}{c}44(43 \%) \\
\left(37,8^{\circ} \mathrm{C}-40^{\circ} \mathrm{C}\right)\end{array}$ & $\begin{array}{c}4(36 \%) \\
\left(37,8^{\circ} \mathrm{C}-38,5^{\circ} \mathrm{C}\right)\end{array}$ & $\begin{array}{c}9(82 \%) \\
\left(38^{\circ} \mathrm{C}-40^{\circ} \mathrm{C}\right)\end{array}$ & $\begin{array}{c}18(47 \%) \\
\left(37,9^{\circ} \mathrm{C}-39,6^{\circ} \mathrm{C}\right)\end{array}$ & $\begin{array}{c}13(30 \%) \\
\left(38^{\circ} \mathrm{C}-39,7^{\circ} \mathrm{C}\right)\end{array}$ \\
\hline \multirow{5}{*}{ Sintomas respiratórios } & Total & $43(42 \%)$ & $7(64 \%)$ & $5(45 \%)$ & $11(29 \%)$ & $20(47 \%)$ \\
\hline & Rinorreia & $10(10 \%)$ & $5(45 \%)$ & $1(9 \%)$ & $3(8 \%)$ & $4(9 \%)$ \\
\hline & Odinofagia & $8(8 \%)$ & $0(0 \%)$ & $0(0 \%)$ & $6(16 \%)$ & $3(7 \%)$ \\
\hline & Dificuldade respiratória & $8(8 \%)$ & $1(9 \%)$ & $2(18 \%)$ & $1(3 \%)$ & $5(12 \%)$ \\
\hline & Hipoxémia & $1(1 \%)$ & $0(0 \%)$ & $0(0 \%)$ & $0(0 \%)$ & $1(2 \%)$ \\
\hline \multirow{2}{*}{ Sintomas gastrointestinais } & Diarreia & $13(13 \%)$ & $0(0 \%)$ & $2(18 \%)$ & $6(16 \%)$ & $3(7 \%)$ \\
\hline & Abdómen agudo & $1(1 \%)$ & $0(0 \%)$ & $0(0 \%)$ & $0(0 \%)$ & $1(2 \%)$ \\
\hline \multirow{2}{*}{ Sintomas neurológicos } & Total & $21(20 \%)$ & $0(0 \%)$ & $0(0 \%)$ & $5(13 \%)$ & $16(37 \%)$ \\
\hline & Cefaleia & $19(18 \%)$ & $0(0 \%)$ & $0(0 \%)$ & $4(11 \%)$ & $15(35 \%)$ \\
\hline \multirow[t]{2}{*}{ Manifestações cutâneas } & Total & $5(5 \%)$ & $0(0 \%)$ & $1(9 \%)$ & $3(8 \%)$ & $1(2 \%)$ \\
\hline & Total & $5(5 \%)$ & $0(0 \%)$ & $0(0 \%)$ & $1(3 \%)$ & $4(9 \%)$ \\
\hline \multirow[t]{2}{*}{ Manifestações sensoriais } & Anosmia & $1(1 \%)$ & $0(0 \%)$ & $0(0 \%)$ & $0(0 \%)$ & $1(2 \%)$ \\
\hline & Disgeusia & $4(4 \%)$ & $0(0 \%)$ & $0(0 \%)$ & $1(3 \%)$ & $3(7 \%)$ \\
\hline $\begin{array}{l}\text { Manifestações } \\
\text { músculo-esqueléticas }\end{array}$ & Total & $9(9 \%)$ & $0(0 \%)$ & $0(0 \%)$ & $1(3 \%)$ & $8(19 \%)$ \\
\hline
\end{tabular}


Tabela 3 - Quadro clínico e alterações laboratoriais

\begin{tabular}{|c|c|c|c|c|c|}
\hline $\begin{array}{l}\text { Doente } \\
\text { (idade) }\end{array}$ & Clínica & $\begin{array}{l}\text { Leucócitos } \\
\text { Linfócitos } \\
\text { Neutrófilos }\end{array}$ & $\begin{array}{l}\text { PCR } \\
\text { PCT }\end{array}$ & Gasimetria capilar & Outro \\
\hline $\begin{array}{l}1 \\
\text { (24 dias) }\end{array}$ & Febre & $\begin{array}{l}\text { Leuc } 1950 / \mu \mathrm{L} \\
\text { Linf } 1139 / \mu \mathrm{L} \\
\text { Neut } 360 / \mu \mathrm{L}\end{array}$ & $\begin{array}{l}\text { PCR } 0,41 \mathrm{mg} / \mathrm{dL} \\
\text { PCT } 0,57 \mathrm{ng} / \mathrm{mL}\end{array}$ & $\begin{array}{l}\mathrm{pH} 7,26 \\
\mathrm{pCO} 248 \mathrm{mmHg} \\
\mathrm{HCO} 319,0 \mathrm{mmol} / \mathrm{L} \\
\text { Lact } 51 \mathrm{mg} / \mathrm{dL}\end{array}$ & ---------- \\
\hline $\begin{array}{l}2 \\
\text { (1 mês) }\end{array}$ & Diarreia & $\begin{array}{l}\text { Leuc } 14200 / \mu \mathrm{L} \\
\text { Linf } 9850 / \mathrm{uL} \\
\text { Neut } 2140 / \mathrm{uL}\end{array}$ & PCR $0,88 \mathrm{mg} / \mathrm{dL}$ & $\begin{array}{l}\mathrm{pH} 7,22 \\
\mathrm{pCO} 242,6 \mathrm{mmHg} \\
\mathrm{HCO} 315,2 \mathrm{mmol} / \mathrm{L} \\
\text { Lact } 41 \mathrm{mg} / \mathrm{dL}\end{array}$ & ----------- \\
\hline $\begin{array}{l}3 \\
\text { (1 mês) }\end{array}$ & Prostração, recusa alimentar & $\begin{array}{l}\text { Leuc } 9440 / \mu \mathrm{L} \\
\text { Linf } 5180 / \mathrm{uL} \\
\text { Neut } 3250 / \mathrm{uL}\end{array}$ & $\mathrm{PCR}<0,03 \mathrm{mg} / \mathrm{dL}$ & $\begin{array}{l}\mathrm{pH} 7,26 \\
\mathrm{pCO} 253,5 \mathrm{mmHg} \\
\mathrm{HCO} 321,1 \mathrm{mg} / \mathrm{dL} \\
\text { Lact } 36 \mathrm{mg} / \mathrm{dL}\end{array}$ & \\
\hline $\begin{array}{l}4 \\
(4 \text { meses })\end{array}$ & Febre & $\begin{array}{l}\text { Leuc } 12460 / \mu \mathrm{L} \\
\text { Linf } 5890 / \mathrm{uL} \\
\text { Neut } 4860 / \mathrm{uL}\end{array}$ & PCR $0,67 \mathrm{mg} / \mathrm{dL}$ & & \\
\hline $\begin{array}{l}\mathbf{5} \\
\text { (11 meses) }\end{array}$ & Adenite cervical & $\begin{array}{l}\text { Leuc } 25420 / \mu \mathrm{L} \\
\text { Linf } 6760 / \mathrm{uL} \\
\text { Neut } 16220 / \mu \mathrm{L}\end{array}$ & PCR $18,5 \mathrm{mg} / \mathrm{dL}$ & & \\
\hline $\begin{array}{l}6 \\
\text { (9 anos) }\end{array}$ & Febre e artralgia & $\begin{array}{l}\text { Leuc } 19990 / \mu \mathrm{L} \\
\text { Linf } 2859 / \mathrm{uL} \\
\text { Neut } 14393 / \mathrm{uL}\end{array}$ & $\begin{array}{l}\text { PCR } 21,1 \mathrm{mg} / \mathrm{dL} \\
\text { PCT } 1,21 \mathrm{ng} / \mathrm{mL}\end{array}$ & -------------- & ----------- \\
\hline $\begin{array}{l}7 \\
(10 \text { anos })\end{array}$ & PIMS-TS & $\begin{array}{l}\text { Leuc } 13140 / \mu \mathrm{L} \\
\text { Linf } 600 / \mathrm{uL} \\
\text { Neut } 11826 / \mathrm{uL}\end{array}$ & $\begin{array}{l}\text { PCR } 31,4 \mathrm{mg} / \mathrm{dL} \\
\text { PCT } 2,43 \mathrm{ng} / \mathrm{mL}\end{array}$ & & $\begin{array}{l}\text { D-dímeros } 2,29 \mathrm{mcg} / \mathrm{mL} \\
\text { NT-proBNP } 11470 \mathrm{pg} / \mathrm{mL}\end{array}$ \\
\hline $\begin{array}{l}8 \\
(15 \text { anos })\end{array}$ & $\begin{array}{l}\text { Oclusão intestinal (divertículo } \\
\text { de Meckel) }\end{array}$ & $\begin{array}{l}\text { Leuc } 7560 / \mu \mathrm{L} \\
\text { Linf } 937 / \mu \mathrm{L} \\
\text { Neut } 6290 / \mu \mathrm{L}\end{array}$ & PCR $0,03 \mathrm{mg} / \mathrm{dL}$ & -------------- & ---------- \\
\hline $\begin{array}{l}9 \\
\text { (15 anos) }\end{array}$ & $\begin{array}{l}\text { Febre, tosse (agravamento da } \\
\text { função renal em transplantado } \\
\text { renal) }\end{array}$ & $\begin{array}{l}\text { Leuc } 7200 / \mu \mathrm{L} \\
\text { Linf } 698 / \mu \mathrm{L} \\
\text { Neut } 6062 / \mu \mathrm{L}\end{array}$ & PCR $0,13 \mathrm{mg} / \mathrm{dL}$ & & $\begin{array}{l}\text { Ureia } 63 \mathrm{mg} / \mathrm{dL} \\
\text { Creat } 1,23 \mathrm{mg} / \mathrm{dL}\end{array}$ \\
\hline
\end{tabular}

Creat: creatinina; Lact: lactato; Leuc: leucócitos Linf: linfócitos; PCR: proteína C reativa; PCT: Orocalcitonina

Uma criança teve necessidade de internamento na $\mathrm{UCl}-$ Ped. A mediana da duração de internamentos foi de 6,5 dias (Tabela 4).

Em relação à terapêutica, o doente com PIMS-TS e o doente com adenite cervical realizaram antibioticoterapia tendo o primeiro necessitado de oxigenoterapia, suporte aminérgico e administração de imunoglobulina. Nenhum doente teve indicação para ventilação invasiva ou não invasiva. Não foi administrada terapêutica antiviral específica a nenhuma criança.
Contactámos os doentes com infeção por SARS-CoV-2 para aferir critérios de cura e manifestações clínicas, com pelo menos 14 dias de evolução da doença (mediana do tempo de seguimento de 29,5 dias). Destes, 87 (84\%) apresentavam critérios de cura (pelo menos um teste negativo ou dois testes nos que estiveram internados com sintomatologia de COVID-19). Do total de infetados, 100 encontravam-se assintomáticos (97\%), sem sequelas, e apenas um estava sintomático (tosse sem outros sintomas ou sinais de gravidade). Em dois casos a evolução foi desconhecida.

Tabela 4 - Internamentos das crianças e adolescentes com infeção por SARS-CoV-2

\begin{tabular}{|c|c|c|c|c|c|}
\hline & $\begin{array}{c}\text { Total } \\
(n=103)\end{array}$ & $\begin{array}{l}\leq 3 \text { meses } \\
(n=11)\end{array}$ & $\begin{array}{c}4-11 \text { meses } \\
(n=11)\end{array}$ & $\begin{array}{c}1 \text { ano }-9 \text { anos } \\
(\mathrm{n}=38)\end{array}$ & $\begin{array}{l}\geq 10 \text { anos } \\
(n=43)\end{array}$ \\
\hline Internamento, n (\%) & $10(10 \%)$ & $5(56 \%)$ & $1(9 \%)$ & $2(5 \%)$ & $2(5 \%)$ \\
\hline $\begin{array}{l}\text { Mediana duração de internamento } \\
\text { (máximo - mínimo) }\end{array}$ & $\begin{array}{c}6,5 \\
(1-16)\end{array}$ & $\begin{array}{c}10 \\
(1-16)\end{array}$ & 4 & $\begin{array}{c}3 \\
(1-5)\end{array}$ & $\begin{array}{c}10 \\
(8-11)\end{array}$ \\
\hline Fatores de risco & & 1 prematuridade & & & \\
\hline Motivo de internamento & & $\begin{array}{l}2 \text { febre } \\
1 \text { diarreia } \\
2 \text { casos sociais }\end{array}$ & 1 adenite cervical & $\begin{array}{l}1 \text { suspeita de artrite } \\
\text { séptica } \\
1 \text { caso social }\end{array}$ & $\begin{array}{l}1 \text { PIMS-TS* } \\
1 \text { oclusão intestinal }\end{array}$ \\
\hline
\end{tabular}


Tabela 5 - Evolução das crianças e adolescentes com infeção por SARS-CoV-2

\begin{tabular}{|c|c|c|c|c|c|}
\hline & $\begin{array}{c}\text { Total } \\
(n=103)\end{array}$ & $\begin{array}{c}\leq 3 \text { meses } \\
(n=11)\end{array}$ & $\begin{array}{c}4-11 \text { meses } \\
(n=11)\end{array}$ & $\begin{array}{c}1 \text { ano }-9 \text { anos } \\
(n=38)\end{array}$ & $\begin{array}{c}\geq 10 \text { anos } \\
(n=43)\end{array}$ \\
\hline \multicolumn{6}{|l|}{ Evolução ( $\geq 14$ dias desde o diagnóstico) } \\
\hline Assintomáticos sem sequelas & $100(97 \%)$ & $10(91 \%)$ & $11(11 \%)$ & $38(38 \%)$ & $41(40 \%)$ \\
\hline Sintomáticos & $1(1 \%)$ & $1(9 \%)$ & $0(0 \%)$ & $0(0 \%)$ & $0(0 \%)$ \\
\hline Desconhecido & $2(2 \%)$ & $0(0 \%)$ & $0(0 \%)$ & $0(0 \%)$ & $2(5 \%)$ \\
\hline Com critérios de cura microbiológica & $87(84 \%)$ & $8(73 \%)$ & $9(82 \%)$ & $35(92 \%)$ & $35(81 \%)$ \\
\hline Sem critérios de cura microbiológica & $14(14 \%)$ & $3(27 \%)$ & $2(18 \%)$ & $3(8 \%)$ & $6(14 \%)$ \\
\hline Morte & $0(0 \%)$ & $0(0 \%)$ & $0(0 \%)$ & $0(0 \%)$ & $0(0 \%)$ \\
\hline
\end{tabular}

Todos os doentes que estiveram internados estavam assintomáticos e apresentavam critérios de cura microbiológica. Não se registaram óbitos durante este período de estudo (Tabela 5). De todos os doentes diagnosticados com infeção por SARS-CoV-2, oito (8\%) voltaram ao SUPed. Um foi internado para terapêutica antibiótica endovenosa por adenite cervical, e os outros não apresentavam critérios de gravidade clínica e tiveram alta para o domicílio.

Relativamente à vacinação com BCG, dos 103 doentes, $78(69 \%)$ tinham sido previamente vacinados, 73 antes do ano de idade. Em quatro doentes (4\%) não foi possível determinar o estado vacinal. No grupo de crianças nascidas a partir de janeiro de 2016, verificamos que 19 das 37 crianças $(51 \%)$ foram vacinadas, $16(43 \%)$ não o foram e em duas (5\%) não foi possível determinar o estado vacinal.

\section{DISCUSSÃO}

À data da ativação do DdP para diagnóstico e acompanhamento de crianças e adolescentes suspeitos ou com infeção confirmada por SARS-CoV-2, já estava bem documentada a menor repercussão desta infeção na criança relativamente ao adulto.,10-12 Por sua vez, foi levantada pela Direção Geral da Saúde (DGS) a obrigatoriedade de internamento de todos os casos confirmados. ${ }^{4}$

A quase totalidade dos doentes pediátricos infetados com SARS-CoV-2 apresentava um contacto positivo confirmado com familiares diretos adultos antes do diagnóstico. Estes dados estão de acordo com outras séries de casos que apontam para a maior incidência da infeção em determinados clusters familiares, com os adultos a apresentarem sintomas mais precocemente. ${ }^{10}$

Os circuitos estabelecidos no atendimento a crianças com suspeita ou infeção confirmada por SARS-CoV-2 permitiram que não fossem identificados casos de infeção nosocomial.

A sintomatologia observada mostra a diversidade e frequência já descrita na literatura relativamente à população pediátrica. ${ }^{12}$ Tal como em duas séries italianas, com $100^{13} \mathrm{e}$ $168^{14}$ crianças, a febre $(54 \% / 82,1 \%)$ foi o sintoma observado mais frequentemente também na nossa amostra (43\%). A dispneia, a diarreia e as náuseas e vómitos (11\% / 9,5\%, $9 \% / 13,1 \%$ e $10 \% / 5,4 \%$, respetivamente) foram descritos com frequências semelhantes às reportadas na nossa série $(8 \%, 13 \%, 10 \%)$. A febre foi preponderante nos lactentes dos quatro aos 11 meses de idade e os sintomas respirató- rios até aos três meses de idade. Não se verificaram quadros respiratórios graves. Nas crianças com idade superior ou igual a 10 anos, detetámos alguns casos de anosmia e disgeusia que são mais frequentes na população adulta. ${ }^{15}$

A requisição de exames complementares de diagnóstico nos doentes pediátricos com COVID-19 deve ser criteriosa, não estando indicada na maioria dos doentes, por se tratar de casos de doença ligeira, ${ }^{5}$ como verificado na nossa amostra. No nosso centro os exames complementares foram solicitados em apenas treze crianças (13\%) com COVID-19, tendo sido utilizados os critérios clínicos habituais.

Os achados analíticos mais comumente descritos em doentes pediátricos são a linfopenia e o aumento da PCR/ $P C T .{ }^{10,12}$ Das nove crianças que realizaram avaliação analítica, observámos quatro casos de linfopenia, um (recém-nascido) de neutropenia e três de elevação da PCR/PCT. Nos três lactentes menores de dois meses de idade com avaliação analítica observámos acidose e hiperlactacidemia transitórias.

A imagiologia torácica das crianças infetadas apresenta significativamente menos alterações sugestivas de SARS-CoV-2 comparativamente aos adultos. ${ }^{16,17} \mathrm{O}$ escasso número de crianças submetidas a radiografia torácica está em linha com as recomendações do American College of Radiology que não incluem a radiografia ou TC torácica para o diagnóstico da infeção por SARS-CoV-2 em idade pediátrica. ${ }^{17,18} \mathrm{Na}$ série italiana de 168 crianças $^{14}$ nenhuma foi submetida a TC torácica.

A baixa probabilidade de complicações e a ausência de evidência fundamentada da utilização de fármacos com ação antivírica em idade pediátrica ${ }^{12}$ motivaram que, desde o início, o protocolo de tratamento adotado no nosso hospital não contemplasse nenhuma indicação formal de tratamento antivírico - e não o utilizámos em nenhum caso.

Apesar do DdP prestar cuidados a crianças consideradas de maior risco de complicações, nomeadamente com doença pulmonar crónica, endocrinológica, metabólica ou imunodeficiências primárias e secundárias, apenas verificámos sete casos $(7 \%)$ de COVID-19 em doentes crónicos. Nenhum teve necessidade de internamento. O doente com transplante renal apresentou um agravamento transitório da função renal, sem outras complicações. A aparente pouca repercussão da pandemia nestas crianças de risco poderá ser devida a um maior cumprimento de regras de 
evicção social por parte dos cuidadores destas crianças, principalmente pelo período do estudo ser coincidente com a declaração de estado de emergência em Portugal e com o fecho das escolas. Com o retomar da atividade escolar e nos meses mais frios do ano, altura em que existe uma maior circulação de outros vírus e risco consequente de co-infeções, a realidade poderá ser outra.

A indicação de internamento seguiu os critérios habituais para quadros clínicos semelhantes com outras etiologias. Devemos ter em conta que a taxa de internamento de $10 \%$ é referente a uma população que recorreu ao SUPed. Dados de uma série italiana com 168 crianças com infeção por SARS-CoV-2, entre março e abril de 2020, ${ }^{14}$ revelaram uma taxa de internamento de $65,1 \%$, com $19,6 \%$ dos doentes a apresentarem co-morbilidades. Contudo, com o evoluir da epidemia e a execução de mais testes diagnósticos, nos dados referidos a 20 de maio de 2020, publicados pelo Ministério da Saúde italiano, ${ }^{19}$ constavam 4241 crianças (menores de 18 anos de idade) com uma taxa de hospitalização de 2,9\%.

Além da criança com PIMS-TS, ${ }^{20,21}$ internámos três crianças com infeção por SARS-CoV-2 e quadros clínico-laboratoriais, que podem corresponder a manifestações inflamatórias raras associadas a COVID-19. ${ }^{22}$ Uma apresentava quadro de abdómen agudo ${ }^{23}$ e linfopenia mas com presença de divertículo de Meckel e duas apresentavam parâmetros inflamatórios elevados associados numa a artralgia ${ }^{24}$ e noutra a adenite cervical, ${ }^{25}$ sem identificação de outro agente infecioso.

A adoção de critérios clínicos e não microbiológicos de alta, sempre que garantidas condições domiciliárias adequadas e ausência de coabitantes pertencentes a grupos de risco, permitiu não prolongar desnecessariamente internamentos hospitalares, tendo-se obtido uma mediana de duração de internamento de 6,5 dias.

As 101 crianças com inquérito telefónico após pelo menos 14 dias de evolução (mediana de tempo de seguimento de 29,5 dias) evoluíram bem, persistindo tosse ligeira apenas numa. Houve $8 \%$ das crianças com infeção por SARS-CoV-2 que foram reobservadas no SUPed, dos quais apenas uma com evolução complicada (adenite cervical).

No início da pandemia, teorizou-se que a vacina BCG pudesse ter um efeito protetor relativamente à COVID-19,,$^{27,28}$ mas não se encontrou até à data evidência para tal, não estando atualmente recomendada a vacinação BCG na prevenção da COVID-19. ${ }^{28,29}$ No nosso estudo, a maioria dos doentes (76\%) tinha sido vacinada. Analisámos separadamente o subgrupo de crianças nascidas após janeiro de 2016, altura em que passaram a ser vacinadas apenas as crianças pertencentes a grupos de risco. ${ }^{30} \mathrm{~A}$ taxa de vacinação neste grupo foi de $51 \%$, sendo superior à taxa de $30,1 \%$ estimada para crianças nascidas em Portugal com um ano de idade referido a 2019. ${ }^{31}$

Em termos de limitações, trata-se de um estudo observacional realizado apenas num Centro Hospitalar, com uma amostra relativamente pequena, embora comparável às séries publicadas. O inquérito epidemiológico e de registo de sintomatologia na apresentação não incluía parâmetros completos de observação clínica. A mediana do tempo de seguimento de 24 dias poderá ser considerada curta para o aparecimento de complicações inflamatórias. ${ }^{31}$

Este artigo é a primeira série de casos portuguesa de infeção por SARS-CoV-2 em idade pediátrica a ser publicada e diz respeito à população pediátrica de um Centro Hospitalar Universitário central.

\section{CONCLUSÃO}

Esta série de 103 casos é apenas descritiva e tem o objetivo de contribuir para uma melhor compreensão desta nova doença na população pediátrica. Implementámos uma estratégia baseada em critérios seguidos para quadros clínicos semelhantes, que motivou um baixo consumo de recursos hospitalares, de exames complementares e de terapêutica, que até agora demonstrou ser segura na abordagem das crianças com infeção suspeita ou confirmada por SARS-CoV-2.

\section{AGRADECIMENTOS}

Agradecemos a todos os profissionais de saúde que lidam diariamente com esta nova doença, em particular aos da nossa instituição, pelo incessante trabalho, assegurando sempre o melhor interesse dos doentes.

\section{PROTEÇÃO DE PESSOAS E ANIMAIS}

Os autores declaram que o projecto foi aprovado pela Comissão de Ética do Centro Hospitalar Universitário de Lisboa Norte e do Centro Académico de Medicina de Lisboa e está de acordo com a Declaração de Helsínquia da Associação Médica Mundial - versão de 2013.

\section{CONFIDENCIALIDADE DOS DADOS}

Os autores declaram ter seguido os protocolos do seu centro de trabalho acerca da publicação de dados.

\section{CONFLITO DE INTERESSES}

Os autores declaram não ter nenhum conflito de interesses relativamente ao presente artigo.

\section{FONTES DE FINANCIAMENTO}

Não existiram fontes externas de financiamento para a realização deste artigo.

\section{REFERÊNCIAS}

1. World Health Organization. WHO Director-General's opening remarks at the media briefing on COVID-19 - 11 March 2020. [consultado 2020 jun 3]. Disponível em: https://www.who.int/dg/speeches/detail/who-directorgeneral-s-opening-remarks-at-the-media-briefing-on-covid-19---11march-2020.
2. Direção Geral da Saúde. Comunicado C160 75 v1. Casos de infeção por novo Coronavírus (COVID-19). Lisboa: DGS; 2020.

3. World Health Organization. Interim guidance, Considerations in the investigation of cases and clusters of COVID-19. Genebra: WHO; 2020.

4. Direção Geral da Saúde. Norma 004/2020, COVID-19: Fase de 
mitigação, abordagem do doente com suspeita ou infeção por SARSCoV-2. Lisboa: DGS; 2020.

5. Sociedade de Infecciologia Pediátrica, Sociedade de Pneumologia Pediárica e do Sono, Secção de Reumatologia Pediátrica. Abordagem do doente pediátrico com COVID-19. Lisboa: SPP; 2020.

6. Sociedade Portuguesa de Cuidados Intensivos Pediátricos. Orientações para a abordagem e tratamento do doente peditrático com COVID-19. Lisboa: SPCIP; 2020.

7. Direção Geral da Saúde. Orientação 02A/2020, Doença pelo novo Coronavírus (COVID-19) - Nova definição de caso. Lisboa: DGS; 2020

8. Galli L, Chiappini E, Schumacher R. After the first wave of COVID-19: reflections from Italy. Pediatr Infect Dis J. 2020;39: e192-4.

9. Associación Española de Pediatria. Documento de manejo clínico del paciente pediátrico y pacientes de riesgo con infección por SARSCoV2. Madrid: AEP; 2020.

10. Zimmermann $P$, Curtis $N$. Coronavirus infections in children including COVID-19: an overview of the epidemiology, clinical features, diagnosis, treatment and prevention options in children. Pediatr Infect Dis J. 2020;39:355-68.

11. Dong $Y$, Mo X, Hu Y, Qi X, Jiang F, Jiang Z, et al. Epidemiology of COVID-19 among children in China. Pediatrics. 2020;145:1-10.

12. Lu X, Zhang L, Du H, Zhang J, Li Y, Qu J, et al. SARS-CoV-2 infection in children. N Engl J Med. 2020;382:1663-5

13. Parri N, Lenge $M$, Buonsenso $D$, Coronavirus infection in Pediatric Emergency Departments (CONFIDENCE) Research Group. Children with Covid-19 in pediatric emergency departments in Italy. N Engl J Med. 2020; 383:187-90.

14. Garazzino S, Montagnani C, Donà D, Meini A, Felici E, Vergine G, et al. Multicentre Italian study of SARS-CoV-2 infection in children and adolescents, preliminary data as at 10 April 2020. Euro Surveill. 2020; 25: 2000600 .

15. Vaira LA, Salzano G, Deiana G, De Riu G. Anosmia and ageusia: common findings in COVID-19 patients. Laryngoscope. 2020;130:1787.

16. Duan YN, Zhu YQ, Tang LL, Qin J. CT features of novel coronavirus pneumonia (COVID-19) in children. Eur Radiol. 2020;30:4427-33.

17. Chen A, Huang J, Liao Y, Liu Z, Chen D, Yang C, et al. Differences in clinical and imaging presentation of pediatric patients with COVID-19 in comparison with adults. Radiol Cardiothorac Imaging. 2020;2:e200117.

18. Society of Thoracic Radiology. COVID-19 Resources. [consultado 2020 jun 24], Disponível em: https://thoracicrad.org/?page_id=2879.

19. Epicentro. [consultado 2020 maio 20]. Disponível em: https://www. epicentro.iss.it/coronavirus/bollettino/Bollettino-sorveglianza-integrataCOVID-19_20-maggio-2020.pdf.
20. European Centre for Disease Prevention and Control. Paediatric inflammatory multisystem syndrome and SARS-CoV-2 infection in children. ECDC; 2020. [consultado 2020 jun 27], Disponível em: https://www.ecdc.europa.eu/sites/default/files/documents/covid-19risk-assessment-paediatric-inflammatory-multisystem-syndrome-15May-2020.pdf.

21. The Centers for Disease Control and Prevention (CDC) Health Alert Network. Multisystem inflammatory syndrome in children (MIS-C) associated with Coronavirus disease 2019 (COVID-19). 2020. [consultado 2020 jun 30], Disponível em: https://emergency.cdc.gov/ han/2020/han00432.asp.

22. Galeotti C, Bayry J. Autoimmune and inflammatory diseases following COVID-19. Nature Rev Rheumatol. 2020;16:413-4.

23. Goshayeshi L, Milani N, Bergqueist R, Sadrzadeh S, Rajabzadeh F, Hoseini B. Covid-19 infection without respiratory symptoms: case report of diagnosing a 14 year-old patient with acute abdomen. Res Square. 2020 (in press). doi: 10.21203/rs.3.rs-27389/v1.

24. Saricaoglu E, Hasanoglu I, Guner R. The first reactive arthritis case associated with COVID-19. J Med Virol. 2020 (in press). doi: 10.1002/ jmv.26296.

25. Lechien J, Chetrit A, Chekkoury-Idrissi Y, Distinguin L, Circiu M, Saussez $\mathrm{S}$, et al. Parotidis-like symptoms associated with COVID-19. Emerg Infect Dis. 2020 (in press). doi: 10.3201/eid2609.202059.

26. Curtis N, Sparrow A, Ghebreyesus TA, Netea MG. Considering BCG vaccination to reduce the impact of COVID-19. Lancet. 2020;395:15456 .

27. Gursel M, Gursel I. Is global BCG vaccination-induced trained immunity relevant to the progression of SARS-CoV-2 pandemic? Allergy Eur J Allergy Clin Immunol. 2020;75:1815-9.

28. World Health Organization. Bacille Calmette-Guérin (BCG) vaccination and COVID-19. [consultado 2020 jun 24]. Disponível em: https://www. who.int/news-room/commentaries/detail/bacille-calmette-guérin-(bcg)vaccination-and-covid-19

29. Despacho n. 8264/2016. Diário da República, II Série, n. ${ }^{\circ} 120$ (2016/06/24). p. 19694.

30. Instituto Nacional de Estatística, DGS/ARS, Sistema VACINAS [consultado 2020 jun 24]. Disponível em: https://www.ine.pt/xportal/ xmain?xpid=INE\&xpgid=ine_indicadores\&indOcorrCod=0009750\&cont exto=bd\&selTab=tab2.

31. Consiglio C, Cotugno N, Sardh F, Pou C, Amodio D, Zicari S, et al. The immunology of multisystem inflammatory syndrome in children with COVID. medRxiv. 2020. doi: 10.1101/2020.07.08.20148353. 